\title{
Postpartum Depression among Women in a Rural Community, Ismailia, Egypt
}

\author{
Hassan AE. Abdelwahid", Nadia M. Mansour, Mosleh A. Ismail \\ Department of Family Medicine, Faculty of Medicine, Suez Canal University, Ismailia, Egypt
}

\begin{abstract}
Background: Postpartum depression (PPD) is a major depressive disorder with possible long-term consequences on the mother and her infant. Despite the reported high prevalence rates, the rates of diagnosis and treatment of this serious problem are low due to lack of early recognition. Aim: Screening for PPD among women during well-baby visits in a rural community. The Specific objectives included: 1) Assessment of the prevalence of PPD and 2) Identification of its independent predictors among the studied women. Patients and Methods: A sample size of $\mathbf{2 1 0}$ women was randomly selected from postpartum women, 6-8 weeks after delivery, during their well-baby visits in a rural community, Ismailia, Egypt. The field-work was conducted from October 15, 2011 to December 10, 2011. The Arabic version of the Edinburgh Postnatal Depression Scale (EPDS) was used for PPD screening. Socio-demographic characteristics of the participants were collected by a predesigned structured questionnaire. Results: Out of 200 screened women who responded to the questionnaires, depression was detected in $22 \%$. Women who perceived interpersonal relationship with their husbands as a poor relationship were 12 times more likely to suffer from postpartum depression than those perceived this relationship as a good one ( $\mathrm{OR}=12$ [95\% Cl $=4.2-34 \cdot 5]$ ). Housewives were more liable to develop postpartum depression ( $O R=3.4]$ ) than working mothers. Postpartum depression, also, was more common among women who delivered normally $(\mathrm{OR}=3.9)$; fed their infants by breast $(\mathrm{OR}=3.8)$; and those who had female infant $(\mathrm{OR}=3.9)$. Conclusion: PPD is a considerable and existing problem among the study group. Opportunistic screening of mothers at well-child visits by family physicians should be conducted for early detection of postpartum depression.
\end{abstract}

Keywords: Postpartum, depression, prevalence, predictors, rural, Ismailia, Egypt

\section{Introduction}

Postpartum depression (PPD) is a type of clinical depression, which can affect women, and less frequently men after childbirth. It is evident that PPD is a common consequence among women in the post partum period. The overall reported international prevalence rates among women are variable in different studies and ranges from $0 \%$ in Singapore to nearly $57 \%$ in Brazil. However, the methodological differences among the studies make the actual prevalence rate unclear $^{(1)}$. PPDis a major depressive disorder with possible long-term consequences on the mother and her infant. The criteria for a major depressive disorder includes five or more symptoms, including depressed mood, markedly diminished interest or pleasure in an activity, appetite disturbance, sleep disturbance, physical agitation or psychomotor retardation, fatigue, feelings of worthlessness, diminished concern or inability to make decisions, and recurrent thoughts of death or suicide ${ }^{(2)}$. 
The Diagnostic and Statistical Manual of Mental Disorders (DSM-IV) specifies that the symptoms of PPD must begin within 4 weeks after delivery ${ }^{(2)}$, but many experts believe that women remain at increased risk for depression for up to 1 year after delivery ${ }^{(3)}$. The PPD has additional adverse effects, not only on the mother, but also on the infant, and the family such as marital distress ${ }^{(4)}$, problems with mother-infant interaction and attachment ${ }^{(5)}$, and adverse behavioural and cognitive effects in the child $^{(6)}$.

The literature demonstrates low rates of help seeking in the population of postpartum women and up to $50 \%$ of individuals with PPD are not diagnosed leading to adverse outcomes for the patient and family. Many of these women revealed a perceived stigma associated with depression and are unable to differentiate between normal transitions to motherhood and PPD symptoms ${ }^{(7-9)}$. These findings confirm the importance of screening for PPD. The new mother encounters the well-baby clinic at least eight times in her infant's first 2 years of life and this represent a good medium for PPD opportunistic screening and health education. Screening can be implemented easily in this setting ${ }^{(10)}$.

The Edinburgh Postnatal Depression Scale (EPDS) is a 10-item self-administered questionnaire that is most commonly used for screening of PPD with high sensitivity and specificity ${ }^{(11)}$. The Arabic version of the EPDS $^{(12-13)}$ has been validated among Arabic women and its psychometric performance is comparable to the original scale. Each item is scored from zero to 3 with possible total scores of zero to 30 . It is recommended that scores greater than or equal to 13 be used to identify women with a major depressive episode that requires further assessment ${ }^{(11)}$. The role of family physician is of a great importance in this regard through planning and conducting such ac- tivity. The aim of the present study was to screen for PPD among women during wellbaby visits in a rural community. The Specific objectives included: 1) Assessment of the prevalence rate of PPD and 2) Identification of the independent predictors of PPD among the study group.

\section{Subjects and Methods}

\section{Study design and setting}

This cross-sectional study was performed at two Family Practice centres that provide primary care to the catchment area in El Mahsma village (one affiliated to Family Medicine Department/Faculty of Medicine/Suez Canal University [FMD/FOM/SCU] and the second one to Ministry of Health and Population [MOHP]). El Mahsma village is a rural community that is located about $25 \mathrm{Km}$ to the west of Ismailia city. It includes 40 hamlets with a total population of about 22000. The target population were postpartum women in El Mahsama village, Ismailia governorate. The study population (sampled population) included postpartum women attending the 2 centres to utilize the well-baby clinic for vaccination 6-8 weeks postpartum.

\section{Subjects}

A sample size of 210 women was calculated and selected from the target population with an estimated prevalence of PPD to be $21 \%$ (from a previous study) ${ }^{(14)}, 95 \%$ confidence level, $6 \%$ margin of error (E) and 10\% non-response rate ${ }^{(15)}$.

The inclusion criteria included: 1) Post partum women (aged $\geq 18$ years), 2) Women attending well baby clinic 6-8 weeks after delivery and 3) Acceptance to participate in the study (informed consent). Those for whom the study procedures were not feasible due to severe dementia, history suggestive of mental retardation, or unstable medical condition were excluded. Systematic random sampling 
method was used in which every third woman presenting to the PHC centres for well-baby clinic to vaccinate her baby was included in the study.

\section{Tools and operational design}

The field-work was conducted from October 2011 to December 2011. Verbal and written consents were obtained from the participants who completed the questionnaires. Socio-demographic characteristics of the participants (age, marital status, marital relationship with the husband, number of children, housing, occupational status, education level, method and place of delivery, method of baby feeding, history of antenatal health problems, and neonatal health problems) and chronic conditions e.g. hypertension, heart disease, diabetes, liver disease, renal disease or pulmonary disease was collected by a designed questionnaire. An experienced PHC physician administered the Arabic version of the EPDS to each participant, for PPD screening. Researchers through structured interview collected data. EPDS questionnaire contains 10 separate questions in which the patient circles the appropriate response. Each item is scored from zero to 3 with possible total scores of 0 to $30^{(12-13)}$. The conventional 13 cut-off score was used for detecting depression, i.e., EPDS more than 13 indicates depressive disorder need more clarification.

\section{Statistical Design}

All statistical analyses were performed using the SPSS software package-version-16. Descriptive statistics and measures of central tendency and dispersion, as well as, appropriate significance tests were applied according to the types of variables. Multiple logistic regression analysis was conducted to determine which factors were independent predictors of depression. Logistic regression coefficients and estimated odds ratios for each of the independent variables in the model were determined. The $p$ value of $<0.05$ was considered the significance cut-off point.

\section{Results}

Out of 210 women, who were screened for PPD 6-8 weeks after delivery, 200 responded to the questionnaires with a response rate of $95 \%$. The non-response rate (5\%) did not affect the validity of the results because it was taken in consideration in sample size calculation. Table (1) shows the socio-demographic characteristics of the studied population. The age of the studied women ranged from 20-42 years with a mean of $28.3 \pm 6.0$ years. However, the majority of the studied women (59.5\%) were in the age group of less than 30 years. Regarding the educational status, more than one third of the study group were qualified from the university (35.5\%). Only 24 (12\%) of women were illiterates and about fortythree percent $(42.5 \%)$ of patients had preparatory \pm 2ry education (not illustrated in table-1). The majority of the women was housewives (63.5\%) and fed their babies by breast feeding (71.5\%). Most of the studied women (85\%) perceived interpersonal relationship with their husbands as a good one and more than half of them (54.5\%) delivered their baby normally (normal vaginal delivery). Out of 200 screened women, PPD was detected in $22 \%(n=43)$ using the EPDS with cut-off point 13 (Figure 1).

The following independent dichotomous variables were subjected to multiple logistic regression analysis with PPD as dependent variable: mothers' age, educational status, working status, relationship with the husband, gender of the baby, neonatal health problems, method of baby feeding, maternal health problems during pregnancy; and delivery method and place. The effect of the overall model was highly significant $\left(\chi^{2}=51.0, p=0.0001\right)$. 

Table 1: Basic characteristics of the study women

\begin{tabular}{|c|c|c|}
\hline Basic characteristics & No. & $\%$ \\
\hline \multicolumn{3}{|l|}{ Age } \\
\hline 1. Less than 30 years & 119 & 59.5 \\
\hline 2. $\geq 30$ years & 81 & 40.5 \\
\hline \multicolumn{3}{|l|}{ Educational level } \\
\hline 1. University certificate & 71 & 35.5 \\
\hline 2. Less than university degree & & \\
\hline $\begin{array}{l}\text { (1ry, preparatory, secondary education, } \\
\text { read and write or illiterate) }\end{array}$ & 129 & 64.5 \\
\hline \multicolumn{3}{|l|}{ Working status } \\
\hline 1. House wife & 127 & 63.5 \\
\hline 2. Working & 73 & 36.5 \\
\hline \multicolumn{3}{|l|}{ Interpersonal relationship(IPR) with her husband } \\
\hline 1. Perceived as a good IPR & 170 & 85.0 \\
\hline 2. Perceived as a poor IPR & 30 & 15.0 \\
\hline \multicolumn{3}{|l|}{ Gender of the baby } \\
\hline 1. Male & 106 & 53.0 \\
\hline 2. Female & 94 & 47.0 \\
\hline \multicolumn{3}{|l|}{ Neonatal health problems } \\
\hline 1. Present & 25 & 12.5 \\
\hline 2. Absent & 175 & 87.5 \\
\hline \multicolumn{3}{|l|}{ Maternal health problems during pregnancy } \\
\hline 1. Present & 26 & 13.0 \\
\hline 2. Absent & 174 & 87.0 \\
\hline \multicolumn{3}{|l|}{ Type of feeding of the baby } \\
\hline 1. Artificial & 57 & 28.5 \\
\hline 2. Breast feeding & 143 & 71.5 \\
\hline \multicolumn{3}{|l|}{ Delivery place } \\
\hline 1. Hospital, $\mathrm{PHC}$, or private & 188 & 94.0 \\
\hline 2. Home & 12 & 6.0 \\
\hline \multicolumn{3}{|l|}{ Delivery method } \\
\hline 1. Cesarean Section & 91 & $45 \cdot 5$ \\
\hline 2. Normal & 109 & 54.5 \\
\hline
\end{tabular}

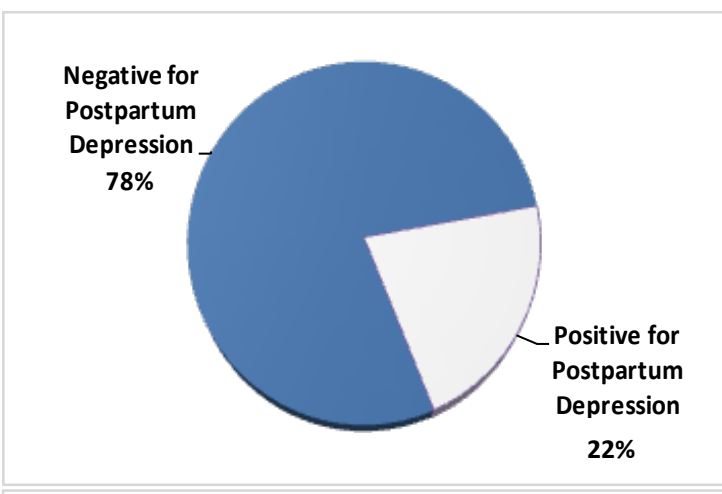

Figure 1: Post-partum depression among the studied women
Table (2) illustrates that the overall percentage of cases that are correctly predicted by the model is $80.5 \%$ (145 cases are observed to be non-depressed and are correctly predicted to be non-depressed and 16 cases are observed to be depressed and are correctly predicted by the regression model. Table (3) illustrates the independent predictors of the regression model. Women who perceived interpersonal relationship with their husbands as a poor one were 12 times more likely to suffer from 
depression than those perceived this relationship as a good one $(\mathrm{OR}=12[95 \% \mathrm{Cl}=4.2-$ 34.5]). Housewives were more liable to develop PPD (OR=3.4 [95\% $\mathrm{Cl}=1.04-10.9])$ than working mothers. Postpartum depression, also, was more common in women who delivered normally $(\mathrm{OR}=3.9 \quad[95 \% \quad \mathrm{Cl}=1.1$ 6.7]); fed their infants by breast ( $\mathrm{OR}=3.8$ [95\% Cl=1.3-11.4]); and those who had female infant $(\mathrm{OR}=3.9[95 \% \mathrm{Cl}=1.3-12.4])$.

Table 2: The observed and predicted values of the depression based on the full logistic regression model

\begin{tabular}{|c|c|c|c|}
\hline \multirow{3}{*}{ Observed } & \multicolumn{2}{|c|}{ Predicted } & \multirow{3}{*}{$\begin{array}{c}\text { Percentage } \\
\text { Correct }\end{array}$} \\
\hline & \multicolumn{2}{|c|}{$E P D S \geq 13$} & \\
\hline & No depression & Depression & \\
\hline Not depressed & 145 & 12 & 92.4 \\
\hline Depressed (EPDS $\geq 13)$ & 27 & 16 & 37.2 \\
\hline Overall Percentage & & & 80.5 \\
\hline
\end{tabular}

Table 3: Multiple Logistic regression analysis: the independent predictors of PPDamong the studied women

\begin{tabular}{|c|c|c|c|c|c|}
\hline \multirow[t]{2}{*}{ Variable (Reference Category) } & \multirow[t]{2}{*}{ B } & \multirow[t]{2}{*}{$p$} & \multirow{2}{*}{$\begin{array}{l}\text { Odds } \\
\text { Ratio }\end{array}$} & \multicolumn{2}{|c|}{$95 \% \mathrm{Cl}$} \\
\hline & & & & $\begin{array}{c}\text { Lower } \\
\text { limit }\end{array}$ & $\begin{array}{l}\text { Upper } \\
\text { limit }\end{array}$ \\
\hline Age of mothers ( $\geq 30$ years) & -0.078 & 0.848 & 0.925 & 0.415 & 2.06 \\
\hline Educational status (less than university degree) & -0.418 & 0.089 & 0.658 & 0.407 & 1.066 \\
\hline Relationship with husband (poor) & 2.493 & $0.001 *$ & 12.096 & 4.241 & 34.502 \\
\hline Gender of the baby (Female) & 1.369 & $0.019^{*}$ & 3.930 & 1.249 & 12.366 \\
\hline Working status (not working) & 1.218 & $0.042 *$ & $3 \cdot 381$ & 1.044 & 10.943 \\
\hline Neonatal health problems (absent) & -0.190 & 0.768 & 0.827 & 0.235 & 2.916 \\
\hline Health problems during pregnancy (absent) & -0.066 & 0.911 & 0.936 & 0.295 & 2.970 \\
\hline Baby feeding method (Breast feeding) & 1.334 & $0.018^{*}$ & 3.796 & 1.262 & 11.420 \\
\hline Delivery place (home) & 1.173 & 0.104 & 3.233 & 0.785 & $13 \cdot 312$ \\
\hline Delivery method (normal delivery) & 1.000 & $0.029 *$ & 2.718 & 1.107 & 6.676 \\
\hline Constant & -8.620 & $0.001 *$ & 0.000 & - & - \\
\hline
\end{tabular}

$\mathrm{Cl}=$ Confidence interval; ${ }^{*}=$ statistically-significant at $\mathrm{p}<0.05 ;{ }^{*}=$ The independent variable with the reference category in parentheses

\section{Discussion}

The current study was conducted on 210 women in a rural community, Ismailia, Egypt. It aimed at identifying prevalence of post-partum depression among postpartum women and predictors of its occurrence among the studied women. Out of 210 women, who were screened for PPD 6-8 weeks after delivery, 200 responded to the questionnaires with a response rate of $95 \%$. It was found that, more than one-fifth of the studied women (22\%) have got postpartum depression as evident by opportunistic screening of women during their visit to well-baby clinic for vaccination of their babies. These results were in partial agreement with the reported results from a study 
conducted by Freeman et al., 2005, on postpartum women at 8-week well-baby visit and showed that, $14.6 \%$ of postpartum women were found to have depression ${ }^{(16)}$.

These results were lower than those reported by Chaudron et al., 2004, in a study conducted to compare prevalence rates of PPD before and after initiation of universal screening for PPD using EPDS. A statistically significant difference was reported before (1.6\%) and after (8.5\%) initiation of screening for PPD $(p<0.001)^{(17)}$. The role of Screening was emphasized by known academic organizations. According to the US Preventive Task Force, formal screening improves detection of depressed patients in primary care settings with the benefits of screening outweighing the potential harm $^{(18)}$. The family physician is in a unique position to screen for PPD because he is the health care provider for children and their mothers in the catchment area. Therefore, it is a strongly recommend for family physicians to consider implementation of a standardized depression screening tool for improving the detection of PPD among postpartum women.

The obtained results from the current study regarding PPD among the studied women (22\%) were consistent with other studies that were conducted either at the level of Arab region [Sudan $(19.5 \%)^{(19)}$, Lebanon $\left.(21 \%)^{(14)}\right]$ or at the level of Egypt [Mansoura city, $(17.9 \%)^{(20)}$ ]. However, the overall prevalence rate of depression observed in the present study was low compared to a study that was conducted in Upper Egypt $(51.8 \%)^{(21)}$. The wide discrepancy in the reported prevalence rates of PPD may be attributed to the methodological differences of the published studies and the socio-demographic characteristics of the studied groups. Despite the reported high prevalence rates and the potentially serious consequences of PPD, the rates of diagnosis and treatment of this serious problem are low due to lack of recognition $^{(22-24)}$. It is unfortunate that the rate of current screening in primary care practices is below $50 \%$ by even the most optimistic estimates $^{(25)}$, and for the clinicians who do screen for depression, the results are not always used for further documented assessment or treatment ${ }^{(22,25)}$.

In the present study younger age of marriage among Egyptian women especially in rural areas was reflected on the age of the study group $(28.3 \pm 6.0)$, that is consistent with other studies conducted in Egypt $^{(20)}$. Some studies ${ }^{(26)}$ considered young age as a risk factor for PPD, on the other hand others could not find the age risk association ${ }^{(4,27)}$. In the current study women who had poor interpersonal relationship with their husbands were 12 times more likely to suffer from depression than those with good relationship (OR=12 [95\% $\mathrm{Cl}=4.2-34.5]$ ), and housewives were more liable to develop depression ( $\mathrm{OR}=3.4[95 \%$ $\mathrm{Cl}=1.04-10.9]$ ) than working mothers. These findings were consistent with the literature that is linking poor relationship satisfaction due family conflict, domestic violence, and unemployment to $\mathrm{PPD}^{(6,20,28,29)}$. Based on the literature, feelings of being unloved by the husband, being separated, or any other marital problems, were found to be associated with PPD in vulnerable females ${ }^{(27)}$.

In the present study depression was more common in women who delivered normally $(O R=3.9)$, a finding that was unexpected by the authors and contradicting another Egyptian study ${ }^{(20)}$. These findings may reflect positive attitude towards caesarian section and is in-need for further investigations. However the current evidence regarding the relationship between method of delivery and PPD is conflicting, with some studies reporting an association, between emergency caesarian section and incidence of PPD, while others not. Conversely there may be an association be- 
tween elective caesarean section and a reduced risk of $\mathrm{PPD}^{(30)}$. The results of the present study showed positive linear association between breast feeding and PPD $(\mathrm{OR}=3.8)$. These findings were inconsistent with the reported results from literature that formula feeding is an independent risk factor for PPD ${ }^{(20,25)}$.

The results obtained from the current study might be explained as a result rather than a cause of PPD due to failure of the depressed mothers to breastfeed their babies. Also, women who had female infant in the present study were more liable $(\mathrm{OR}=3.9)$ to develop depression a finding that reflects positive attitude towards boys who are believed to be superior than females especially in rural communities $^{(20,31,32)}$.

In conclusion, PPD is a considerable and existing problem among the studied women. Opportunistic screening of mothers at well-child visits throughout the first postpartum year by family physicians using the EPDS as standardized screening tool should be conducted for early detection of depression. In light of the results of present study, more research work is needed to assess objectively the unexpected predictors of PPD e.g. normal vaginal delivery versus caesarian section and breast feeding versus artificial feeding.

\section{Limitation of the Study}

The obtained results cannot be extrapolated or generalized on the Egyptian community because the study was conducted only in a rural community. Further studies representing urban and Bedouin communities are needed to give an overall view of PPD in Egypt.

\section{Disclosure}

There is no conflict of interest for all authors and the study was not finically supported from any institute or company.

\section{Acknowledgment}

The authors would like to acknowledge the family physicians and nurses who participated in data collection.

\section{References}

1. Halbreich U, Karkun S: Cross-cultural and social diversity of prevalence of postpartum depression and depressive symptoms. J.Affect.Disord. 2006, 91(2-3):97-111.

2. American Psychiatric Association: Diagnostic and Statistical Manual of Mental Disorders, 4th ed. (DSM-IV). Washington, DC: American Psychiatric Association, 2000.

3. Canadian Mental Health Association. Postpartum depression. Available from: http://www.cmha.ca/mental_health/postpa rtum-depression. Accessed December 13, 2012.

4. Beck CT. Predictors of postpartum depression. Nurs Res. 2001; 50 (5):275-285.

5. Righetti-Veltema M, Bousquet A, Manzano J. Impact of postpartum depressive symptoms on mother and her 18-month-old infant. Eur Child Adolesc Psychiatry. 2003; 12 (2): $75-83$.

6. Grace SL, Evindar A, Stewart DE. The effect of postpartum depression on child cognitive development and behavior: a review and critical analysis of the literature. Arch Womens Ment Health. 2003; 6(4): 263-274.

7. McCarthy M, McMahon, C. Acceptance and experience of treatment for postnatal depression in a community mental health setting. Health Care Women Int. 2008; 29(6), 618-637.

8. McGarry J, Kim H, Sheng X, Egger M, Baksh L. Postpartum depression and help-seeking behavior. J Midwifery Womens Health. 2009; 54(1), 50-56.

9. Riecher-Rössler A, Hofecker Fallahpour M. Postpartum depression: Do we still need this diagnostic term? Acta Psychiatr Scand Suppl. 2003; 108(418), 51-56.

10. Perfetti J, Clark R, Fillmore CM. Postpartum depression: Identification, screening, and treatment. WMJ. 2004;103(6), 56-63.

11. Cox JL, Holden JM, Sagovsky R. Detection of postnatal depression. Development of 
the 10-item Edinburgh Postnatal Depression Scale. Br J Psychiatry. 1987;150:782786.

12. Ghubash R, Abou-Saleh MT, Daradkeh TK. The validity of the Arabic Edinburgh Postnatal Depression Scale. Soc Psychiatry Psychiatr Epidemiol. 1997;32(8):474-476.

13. Department of Health, Government of Western Australia. THE EDINBURGH POSTNATAL DEPRESSION SCALE-Translated Versions. 2006. Available at: http://www. folkhalsoguiden.se/upload/Psykisk\%20H\%C3 \%A4lsa/Edinburgh\%20Depression\%20Scale\%2 oTranslated\%20Government\%20of\%20West ern\%20Australia\%20Department\%200f\%20He alth.pdf. Accessed June 19, 2012.

14. Chaaya M, Campbell OM, El Kak F, Shaar D, Harb H, Kaddour A. Postpartum depression: prevalence and determinants in Lebanon. Arch Womens Ment Health. 2002; 5,(2): 65-72

15. Dawson B, Trapp RG: Basic and clinical biostatistics. 4th ed. USA: McGraw-Hill; 2004.

16. Freeman MP. Wright $\mathrm{R}$, Watchman $\mathrm{M}$, et al. Postpartum depression assessments at well-baby visits: Screening feasibility, prevalence, and risk factors. J Womens Health. 2005; 14(10), 929-935.

17. Chaudron LH, Szilagyi PG, Kitzman HJ, Wadkins HI, Cornwell Y. Detection of postpartum depressive symptoms by screening at well-child visits. Pediatrics. 2004; 113(3), 551-558.

18. United States Preventive Services Task Force. Screening for depression: recommendations and rationale. Ann Intern Med.2002;136:760- 764

19. Sati HA. Prevalence of postnatal depression among Sudanese women and the associated risk factors. The Sudanese Journal of Psychiatry. 2011; 1:153-165.

20. Saleh el-S, El-Bahei W, Del El-Hadidy MA, Zayed A. Predictors of postpartum depression in a sample of Egyptian women. Neuropsychiatr Dis Treat. 2013:9 15-24

21. Mohamed NA, Mahmoud GA, Said NA, Abdelhafez HA, Maklof A MA. Postpartum depression: prevalence and predictors among women at El Eman's specialized hospital. J Am Sci. 2011; 7(12):1-4.
22. Georgiopoulos AM, Bryan TL, Wollan P, Yawn BP. Routine screening for postpartum depression. J Fam Pract. 2001; 50: 117122.

23. Evins GG, Theofrastous JP, Galvin SL. Postpartum depression: a comparison of screening and routine clinical evaluation. Am J Obstet Gynecol. 2000; 182(5): 1080-1082.

24. Hearn G, Iliff A, Jones I, et al. Postnatal depression in the community. $\mathrm{Br} J$ Gen Pract. 1998; 48(428): 1064-1066.

25. Seehusen DA, Baldwin LM, Runkle GP, Clark G. Are family physicians appropriately screening for postpartum depression? J Am Board Fam Pract.2005; 18(2): 104-112.

26. Wolff AW, De Andraca I, Lozoff B. Maternal depression in three Latin American samples. Soc Psychiatry Psychiatr Epidemiol. 2002;37(4): 169-176.

27. O'Hara MW, Swain AM. Rates and risk of postpartum depression-a meta-analysis. Int Rev Psychiatry. 1996; 8:37-54.

28. Ryan D, Milis L, Misri N. Depression during pregnancy. Can Fam Physician. 2005; 51 (8): 1087-1093.

29. Logsdon MC, Usui W. Psychosocial predictors of postpartum depression in diverse groups of women. West J Nurs Res. 2001; 23(6):563-574.

30. Patel RR, Murphy DJ, Peters TJ. Operative delivery and postnatal depression: a cohort study. BMJ. 2005; 330(7496):879.

31. Patel V, Rodrigues M, DeSouza N. Gender, poverty, and postnatal depression: a study of mothers in Goa, India. Am J Psychiatry. 2002; 159 (1): 43-47.

32. Lee DT, Yip AS, Leung TY, Chung TK. Identifying women at risk of postnatal depression: prospective longitudinal study. Hong Kong Med J. 2000; 6 (4):349-354. 